\title{
Bicềitica
}

$\triangleright$ Amparo de Jesús Zárate Cuello*

.012 Bioética

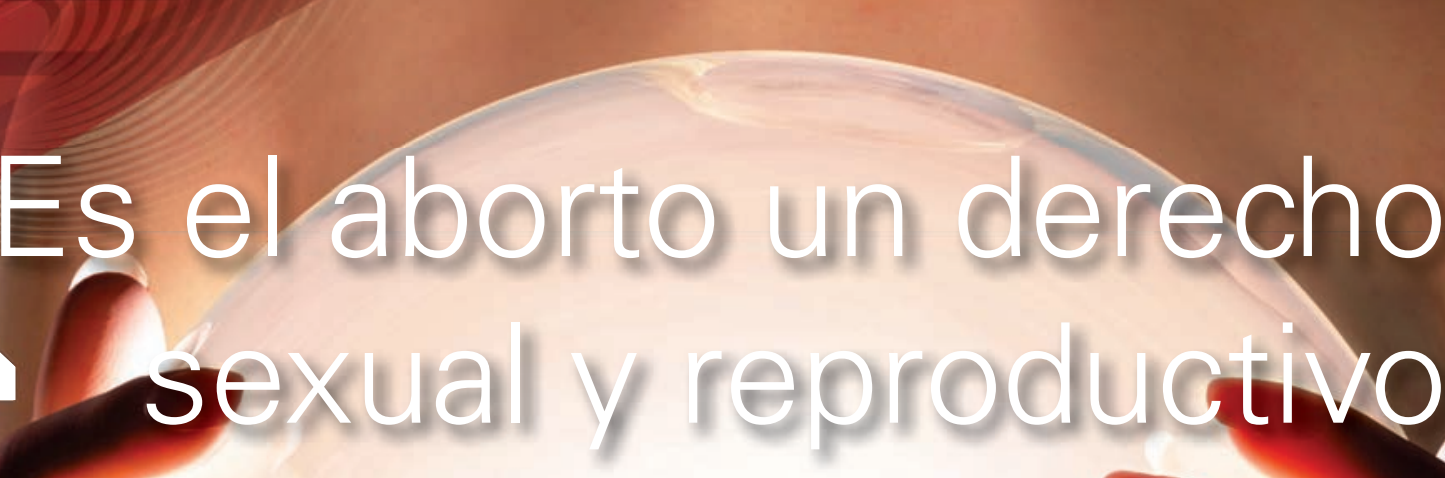

\section{de. la}

rujer?

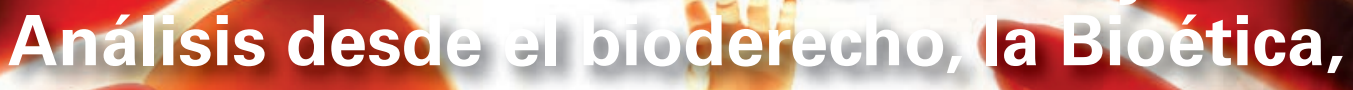
la piojoviliticah ta biojuritica Fn Estados Utilo oss, España y Colombia

ABORTION ASA SEXUAL AND REPRODUCTIVE RIGHT FOR WOMEN? A REVIEW FROMII BIOLAW, BIOETHICS, BIOPOLITICS AND BIOJURIDICS INTHE UNITED STATES, SPAVINAND COLOMBIA

É O ABORTO UIVI DIREITO SEXUAL E REPRODUTIVO DA MULHER? ANÁLISE A PARTIRI DO BIODIREITO, A BIOÉTICA, A BIOPOLÍTICA E 
RESUMEN

A través de la historia, la mujer ha buscado el reconocimiento de sus derechos. Su lucha por la emancipación ha sido fructífera; sin embargo, hasta el presente no ha logrado equipararse con el género masculino en cuanto a la democracia de las oportunidades. En el camino hacia la consecución de sus derechos, se pone de manifiesto su interés en la interrupción del continuum biológico de su función reproductiva, lo que socava la esencia misma del comienzo de la vida humana: el nasciturus que se gesta en su vientre. Así es como en el presente artículo se dilucida el análisis sobre los denominados derechos sexuales y reproductivos a la luz del bioderecho, la Bioética, la biopolítica y la biojurídica; los cuales han sido tratados en la filosofía de grupos feministas, de defensa de la vida y la familia nuclear, que se han hecho sentir en la Conferencia sobre Población y Desarrollo (El Cairo, 1994) y la Cuarta Conferencia Mundial sobre la Mujer (Beijing, 1995).

\section{Palabras clave}

Derechos sexuales y reproductivos de la mujer, bioderecho, bioética, biopolítica, derechos humanos.

\section{ABSTRACT}

Throughout history, women have sought recognition of their rights. Their struggle for emancipation has been fruitful; however, to date it hasn't reached equality with the male gender in the democracy of opportunities. In the way to achieve their rights is exposed their interest in the interruption of the biological continuum of their reproductive function, undermining the very essence of the beginning of human life, the unborn child that is growing in her belly. Thus, in this paper the analysis has been elucidated in the light of Biolaw, Bioethics, Biopolitics and Biojuridic on the so called sexual and reproductive rights which have been dealt in the philosophy of feminist groups, life defense and the nuclear family, taking effect since the Conference on Population and Development (Cairo, 1994) and the Fourth World Conference on Women (Beijing, 1995).

\section{Keywords}

Sexual and reproductive rights in women, biolaw, bioethics, biopolitics, human rights.

\section{RESUMO}

Ao longo da história, as mulheres têm procurando o reconhecimento dos seus direitos. Sua luta pela emancipação tem sido frutífera; no entanto, até hoje não tem conseguido se equiparar com o gênero masculino no enquanto a democracia das oportunidades. No caminho para a consecução de seus direitos, põe-se de manifesto seu interesse na interrupção do continuum biológico de sua função reprodutiva, minando a essência mesma do início da vida humana: o nasciturus que se está gestando no ventre. É assim que neste artigo explica-se a análise dos chamados direitos sexuais e reprodutivos à luz do biodireito, a Bioética, a biopolítica e a biojurídica; os quais foram tratados na filosofia de grupos feministas, de defesa da vida e da família nuclear, que se fizeram sentir durante a Conferência sobre População e Desenvolvimento (El Cairo, 1994) e na Quarta Conferência Mundial sobre a Mulher (Beijing, 1995).

\section{Palavras-chave}

Direitos sexuais e reprodutivos da mulher, biodireito, bioética, biopolítica, biojurídica, direitos humanos. 


\section{INTRODUCCIÓN}

A través de la historia, la mujer, como miembro de la familia Homo sapiens, ha buscado el reconocimiento de sus derechos, los cuales le habían sido desconocidos; sobre todo los relacionados con los ámbitos educativo y laboral. Anteriormente, su función era esencialmente procreadora en detrimento de sus libertades individuales, sueños y prospectivas de crecimiento personal y laboral, dentro de la dinámica del desarrollo político, económico y social de los Estados.

Históricamente, ha sido innegable la subordinación de la mujer frente al hombre en la sociedad; esta ha sido considerada en un segundo lugar de importancia, y su cometido principal era consuetudinariamente ser madre. Su lucha por la emancipación ha sido fructífera, ha generado cambios significativos en diversos roles dentro de la llamada globalización en la aldea planetaria, pero no ha logrado equipararse con el género masculino en cuanto a la democracia de las oportunidades. Para ello, los grupos feministas se han dado a la tarea de crear estrategias ideológicas que les han permitido impulsar proyectos y medidas radicales en defensa de la mujer, en los entornos económico, político y social, que han trascendido, inclusive, al ámbito legislativo con el fin de asegurar el avance y el desarrollo pleno de la mujer. El objetivo de estos proyectos es garantizar el ejercicio y el goce de los derechos humanos y las libertades fundamentales en igualdad de condiciones con el hombre.

Así es como en la Convención sobre la Eliminación de Todas las Formas de Discriminación contra la Mujer (CETFDCM), adoptada por la Asamblea General de las Naciones Unidas el 18 de diciembre de 1979¹ (ONU, 1979), se tuvo el propósito de buscar la igualdad entre géneros, a partir de la modificación del rol de la mujer en la sociedad y la familia, asumiendo tareas o labores que por tradición las realizaba el hombre como responsable del sustento familiar. De igual manera, se consagra la no discriminación contra la mujer.

En cuanto a la consigna de la igualdad de género, surge como un tema relevante dentro de la filosofía de la literatura del bioderecho, la Bioética, la biopolítica y la biojurídica la acepción de los derechos sexuales y reproductivos de la mujer, que tienen como antecedentes diversas conferencias, convenciones y declaraciones, como se puede evidenciar.
Respecto al tema sub examine, en la Asamblea General de la ONU se expresó que: "El tamaño de la familia debe ser la libre opción de la familia" (ONU, 1966). Además, en la Proclamación de Teherán, que surge de la Conferencia Internacional de Derechos Humanos, celebrada en 1968, se reconoce, por primera vez, el derecho de los padres a determinar el número de hijos que deseen tener: "La comunidad internacional debe seguir velando por la familia y el niño. Los padres tienen el derecho humano fundamental de determinar libremente el número de sus hijos y los intervalos entre los nacimientos" (ONU, 1968).

Posteriormente, en la Conferencia Mundial de Población en Bucarest, que tuvo lugar en 1974, se hace una ligera modificación, se otorga el derecho a todas las parejas y todos los individuos a determinar el número de hijos que deseen tener, y no limitarlo únicamente a los "padres", entendidos, para el caso, como el hombre y la mujer dentro de un matrimonio constituido legalmente.

Cinco años después, en la Convención sobre la Eliminación de Todas las Formas de Discriminación contra la Mujer, aprobada por la Asamblea General de la ONU en 1979, se da reconocimiento, en un primer documento, a los derechos humanos de la mujer relativos al "acceso a servicios de atención médica, inclusive los que se refieren a la planificación de la familia". Así mismo, se le garantizan los "servicios apropiados en relación con el embarazo, el parto y el periodo posterior al parto, proporcionando servicios gratuitos cuando fuere necesario, y le asegurarán una nutrición adecuada durante el embarazo y la lactancia" (ONU, 1979). En otro aparte, se hace referencia a la igualdad entre hombres y mujeres: "Los mismos derechos a decidir libre y responsablemente el número de sus hijos y el intervalo entre los nacimientos y a tener acceso a la información, la educación y los medios que les permitan ejercer estos derechos" (ONU, 1979).

Más tarde, se darían dos escenarios propicios de discusión: el primero fue la Conferencia Internacional sobre la Población y el Desarrollo en México, en 1984, y la Conferencia Mundial para el Avance de la Mujer, realizada en Kenia en 1985, de la que se desprenden las Estrategias de Nairobi, aprobadas por la Asamblea General de las Naciones Unidas en diciembre de 1985. En ambas cumbres se tratan aspectos relacionados con la salud reproductiva, y esta se define como el "derecho humano básico de todas las parejas y las personas de decidir libre e informadamente el número y espaciamiento 
de sus hijos" (10g). Y se destaca que "la capacidad de la mujer de controlar su propia fecundidad constituye una base importante para el goce de otros derechos" (7a). También se menciona que los Gobiernos deben "como una cuestión urgente: "poner a disposición la información, la educación y los medios para que mujeres y varones puedan tomar decisiones sobre su número de hijos deseados"2 (ONU, 1985).

Por otra parte, la Conferencia Mundial de Viena sobre Derechos Humanos (1993) enuncia: “[...] la importancia del disfrute por la mujer del más alto nivel de salud física y mental durante toda su vida. [...] la igualdad de condición y los derechos humanos de la mujer, así como a la igualdad de acceso a la educación a todos los niveles [...] el derecho de la mujer a tener acceso a una atención de salud adecuada y a la más amplia gama de servicios de planificación" (artículo 41) (ONU, 1993). Pero es la Conferencia Internacional de las Naciones Unidas sobre Población y Desarrollo, realizada en El Cairo, en septiembre de 1994, donde se promulgaría de una manera más elocuente lo atinente al concepto de salud reproductiva y derechos reproductivos:

Los derechos reproductivos abarcan ciertos derechos humanos que ya están reconocidos en las leyes nacionales, en los documentos internacionales sobre derechos humanos y en otros documentos pertinentes de las Naciones Unidas aprobados por consenso. Esos derechos se basan en el reconocimiento del derecho básico de todas las parejas e individuos a decidir libre y responsablemente el número de hijos, el espaciamiento de los nacimientos y el intervalo entre estos y a disponer de la información y de los medios para ello y el derecho a alcanzar el nivel más elevado de salud sexual y reproductiva. También incluye su derecho a adoptar decisiones relativas a la reproducción sin sufrir discriminación, coacciones ni violencia, de conformidad con lo establecido en los documentos de derechos humanos. (ONU, 1995a)

Así es como se puede afirmar que: "Los derechos reproductivos tienen suancla conceptual a nivel internacional en la Conferencia Internacional realizada en 1994 sobre la Población y el Desarrollo (CIPD). Programa de Acción que podría decirse tiene la primicia al reclamar la probidad legal internacional sobre el término 'derechos sexuales'" (Miller y Roseman, 2011). Además, este encuentro se destacó por la numerosa asistencia, participación, y, sobre todo, por los compromisos que propuso a las naciones participantes para mejorar los aspectos tratados ${ }^{3}$.

Al mismo tiempo, aunque esta conferencia estableció los derechos reproductivos como una aplicación aceptable de los derechos, también incluyó, explícitamente, un lenguaje de compromiso sobre el derecho de acceso al aborto: cuando sea legal debe ser accesible, y donde sea ilegal, las mujeres no deberían morir o enfrentar la morbilidad a causa de los efectos del aborto ilegal e inseguro (Berer, 2009).

En la Cuarta Conferencia Mundial sobre la Mujer, que tuvo lugar entre el 4 y el 15 de septiembre de 1995 en Beijing, se dio la refrendación de las temáticas tratadas en anteriores congregaciones, y se reiteró el legítimo reconocimiento de los derechos femeninos, incluyendo explícitamente el derecho de la mujer a decidir y controlar su sexualidad ${ }^{4}$ (ONU, 1995b), además se consideró la necesidad de que los países revisaran las leyes que criminalizan el aborto. En la Conferencia de Beijing también se estableció que:

- No debe promoverse el aborto como un método de planificación familiar.

- Debería reducirse la incidencia del aborto mediante el acceso a la planificación familiar.

- Donde es legal, el aborto debería ser seguro.

- Donde es ilegal, deberían tratarse las consecuencias de los abortos ilegales o inseguros.

- Es preciso y urgente considerar la posibilidad de revisar las leyes que prevén medidas punitivas contra las mujeres que han tenido abortos ilegales. (ONU, 1995a)

Estas consideraciones fueron reafirmadas en las sesiones quinquenales de seguimiento de los planes de acción de Beijing y El Cairo, respectivamente. En tal sentido, las conferencias de El Cairo y Beijing plantean importantes discusiones en la agenda mundial, pues al hablar con un significado un poco más claro acerca de los derechos humanos en salud reproductiva y sexual, se abrieron dos vertientes de opinión y escenarios de discusión: el primero, un cambio en el contexto político, y el segundo, la evolución del debate conceptual (Miller y Roseman, 2011), que abordaremos en tres países paradigmáticos: Estados Unidos, España y Colombia. 


\section{ABORTO, DERECHOS SEXUALES Y DERECHOS REPRODUCTIVOS: CASOS USA, ESPAÑA Y COLOMBIA}

Resulta interesante el análisis de las diferentes posturas que respecto al aborto tienen los Estados, y la forma como esas biopolíticas que se entraman en los aspectos culturales,

morales, sociales y económicos, entre otros, se van consolidando dentro de cada país. Es importante tener en cuenta las diferencias sustanciales que existen en las legislaciones y normativas que propone cada Gobierno, el órgano legislativo que actúa de acuerdo con las circunstancias de las biopolíticas públicas del momento, influenciado por diversas posturas ideológicas, en muchos casos, opuestas entre sí.

Esta polarización propone, enriquece el debate y plantea cuestiones a dirimir por parte del entorno del bioderecho, la Bioética y la biojurídica5; el primero, aborda las consideraciones fácticas sobre los dilemas y los polilemas que se le presentan a la Bioética, y juridifica, bajo la biolegislación, aspectos concernientes al comienzo, el desarrollo y el final de la vida humana; por consiguiente, la biojurídica examina y dilucida los aspectos filosóficos del derecho, desde la mirada de la dignidad humana y los derechos humanos, como pilar fundamental que deberían observar los ordenamientos jurídicos y la biojurisprudencia de los diferentes estrados judiciales.

En este orden de ideas, el aborto es interpretado, por parte de algunas biolegislaciones como la española, el Common Law en Estados Unidos y la biojurisprudencia en Colombia, como un derecho sexual y reproductivo de la mujer. Teniendo en cuenta las consecuencias de esta diferenciación en la evolución de la legislación alrededor del mundo sobre el tema de las regulaciones acerca del comienzo de la vida, en aspectos morales, filosóficos, económicos y sociales, se presenta la situación sociolegislativa actual en las colectividades de Estados Unidos, España y Colombia, fundamentada en las decisiones de trascendencia biopolítica y biojurídica confrontadas con el bioderecho.

\section{EL ABORTO EN LOS ESTADOS UNIDOS: COMMON LAW}

En Estados Unidos coexisten dos niveles jurídicos: el derecho federal, donde el Gobierno central se impone a todos los habitantes del país y, por otro lado, existe el derecho local en el que cada uno de los Estados tiene autonomía y competencia para establecer sus normas.
Esta es precisamente la situación en el caso del aborto, que ha tenido su escenario de discusión con diferentes tendencias filosóficas a nivel legislativo, tanto federal como local, que finalmente llegan a conocimiento de la Corte Suprema, la cual por más de tres décadas ha venido afrontando problemáticas a favor y en contra del comienzo de la vida humana.

La evolución de la biojurisprudencia respecto al tema del aborto, como una de las biopolíticas del control de la natalidad, contempla diversas posturas que plantean si se debe poner o no fin a la vida, quién puede realizar esta práctica y cómo se debe ejercer control sobre el ser humano en gestación, lo que se plantea en los siguientes casos. Así es como en la Sentencia de 1965, Griswold v. Connecticut, la Corte Suprema suprime la prohibición vigente desde 1879 sobre el uso de cualquier sustancia para el control de la natalidad 6 .

Historiográficamente, se colige que algunas de las sentencias tuvieron que ser revisadas y replanteadas en confrontación a los precedentes y la evolución de las normativas, adelantos tecnológicos y fenómenos sociopolíticos, por solo mencionar algunos. Justamente, la llamada determinación de la Corte Suprema Roe v. Wade ${ }^{7}$ que estableció que las mujeres poseían un derecho constitucionalmente protegido al aborto en los estadios tempranos de embarazo ${ }^{8}$, fue la primera decisión proferida por ese estrado judicial en la democracia estadounidense en la cual se ponía de manifiesto una "libertad" pro aborto. Esta situación años más tarde daría lugar a lo que se conocería como la iniciativa ProChoice ${ }^{9}$, la postura según la cual las mujeres se adjudican la decisión del aborto.

Sobre el particular, lan Shapiro (2009) afirma que "las creencias poderosamente sostenidas de que las mujeres tienen derecho al control soberano de sus cuerpos colisionan con creencias igualmente firmes respecto a que el embarazo acarrea la responsabilidad "aun si no es bienvenida de llevar el embarazo a término" (2009).

El sustento de la decisión Roe v. Wade fue el punto de partida para los subsecuentes debates sobre el aborto, pues permitió poner sobre la mesa la necesidad de una legislación sobre el tema; aun en presencia de la liberación sexual, que trajo consigo la era del rock and roll con su movimiento hippie, no existía en 1960 una ley federal, y en muchos de los Estados de la unión se había prohibido completamente la práctica, con excepción de la situación de riesgo de la vida de la madre a causa del embarazo. 
No obstante, en 1972 se promulga la decisión Eisenstadt v. Baird (citado por Shapiro, 2009) que reza: "el derecho a la intimidad sí significa algo, es el derecho del individuo, soltero o casado, a no sufrir la intromisión del Gobierno en materias que afectan tan fundamentalmente a una persona como la decisión de engendrar o la de tener un hijo". La cual, si bien es insinuativa en ciernes de una planificación familiar, no es impositiva en la instauración del aborto.

A partir del fallo del caso Roe vs. Wade, en los años siguientes surgieron discusiones basadas en diferentes puntos de vista sobre el tema; pues lo que para algunos sectores de la opinión era satisfactorio, para otros era una política muy liberal. Esta situación posteriormente trajo modificaciones a la ya polémica decisión y condujo, entre otras, a la discusión sobre la necesidad de la adolescente y la mujer adulta de notificar o solicitar autorización a su pareja o acudientes para poder realizarse el aborto ${ }^{10}$. Dicho asunto variaría de acuerdo con la normativa vigente en cada Estado y se aplicaría en consecuencia.

Ya para la década del noventa se presentó un nuevo asunto de discusión, conocido como la carga indebida"1, que salió a la luz en la decisión de los temas tratados en las sentencias proferidas ulteriormente. Por otra parte, fue de importancia el caso Planned Parenthood of Southeastern Pennsylvania vs. Casey, en el cual la Corte Suprema, una vez más dividida, reafirmó el holding o sustento básico de Roe vs. Wade, separándolo del esquema de análisis que posibilitaba el aborto basado en trimestres, ahora en desuso, y atándolo, en cambio, a la noción de cargas indebidas (Shapiro, 2009, p. 9).

Con la llegada de George W. Bush al poder en el comienzo del tercer milenio, se incentivó una mirada más conservadora hacia el tema del aborto; el mandatario promovió "iniciativas a favor de la vida" como, por ejemplo, el declarar el 22 de enero como el Día Nacional de la Santidad de la Vida Humana. Dentro de la misma línea de pensamiento, el 25 de septiembre de 2002 se aprueba, por parte de la Cámara de Representantes del Congreso, un proyecto de ley que amplía los márgenes de la objeción de conciencia de médicos, seguros e instituciones sanitarias. Más aún, la ley permite que los hospitales se nieguen a realizar abortos y las compañías de seguros a pagarlos sin que pierdan la financiación federal (Amecopress, 2008). También en una sucesión de reformas legislativas, el 5 de noviembre de 2003, el presidente Bush firmó la Ley de Prohibición del Aborto por Nacimiento Parcial ${ }^{12}$.
Respecto al tema del aborto, la biojurisprudencia ha evolucionado hasta contemplar diversas posturas acerca de cómo se debe ejercer control sobre el ser humano en gestación.

En contraposición, cuando culminó el Gobierno Republicano de Bush de filosofía conservadora, tomó el mandato el Partido Demócrata de la mano de Barack Obama, quien propuso una postura de liberalización de las políticas sexuales, que derrumbaría muchas de las restricciones y normatizaciones que respecto del aborto había implantado el Gobierno de Bush. Finalmente, para el año 2012, poco después de ser reelegido, y pasado su primer periodo presidencial, Obama desataría una gran polémica en Estados Unidos; el 4 de septiembre adoptó una plataforma política dentro de la cual apoyaba el aborto, las uniones gay y los anticonceptivos (Cassata, 2012).

Indudablemente, la sentencia Roe $v$. Wade abrió la puerta al aborto en Estados Unidos; el 22 de enero de 2013 se cumplieron cuatro décadas sobre esta polémica (Mundo.es, 2013) que tiene relación con el comienzo de la vida humana, y que se suscita entre los que defienden el valor de la vida y las voces pro aborto -los primeros conmemoran cuarenta años de luchas por el derecho a la vida (Parker, 2013) y los segundos celebran cuarenta años de justicia reproductiva (Associatedpress, 2013).

Actualmente, se observa que ocho Estados obligan a la mujer a realizarse ecografías para ver las condiciones del feto antes de someterse al aborto. La más reciente encuesta de Gallup arrojó que el 39 \% de los norteamericanos aprueban lo dictaminado en la sentencia Roe v. Wade, mientras que el $18 \%$ dicen estar en contra y el $41 \%$ manifiestan no saber lo suficiente para tomar una decisión (Gallup, 2013). 
Los jueces Warren E. Burger, Potter Stewart, Lewis F. Powell y Harry Blackmun (citado por George, 2009), que adoptaron la decisión de Roe $v$. Wade con el nombre de derecho a la privacidad, en acopio a la cláusula del debido proceso de la Decimocuarta Enmienda de la Constitución, crearon una licencia para matar a los no nacidos. Bajo el entendido de que "el aborto legal era una política humana e iluminada, que aliviaría la carga de muchas mujeres y niñas para aliviar el enorme costo para la sociedad de una alta tasa de natalidad entre las mujeres indigentes (a menudo solteras). Parecían alegremente asumir que el aborto se puede integrar fácilmente en el tejido de la vida social y política estadounidense".

De lo anterior se colige que en Estados Unidos el aborto está incluido a manera de derecho sexual y reproductivo de la mujer; ella es quien resuelve la posible interrupción o continuidad del embarazo, amparada en las políticas gubernamentales y las decisiones de los jueces. Así, se reconoce el derecho al aborto en el Common Law anglosajón como un avance en el reconocimiento de los derechos de la mujer ${ }^{13}$.

\section{ABORTO EN ESPAÑA: BIODERECHO}

Ahora el sub examine le corresponde al ordenamiento jurídico español con la Ley Orgánica 2 del 3 de marzo de 2010 de salud sexual y reproductiva y de la interrupción voluntaria del embarazo; cuyo objeto es "garantizar los derechos fundamentales en el ámbito de la salud sexual y reproductiva, regular las condiciones de la interrupción voluntaria del embarazo y establecer las correspondientes obligaciones de los poderes públicos" (Ley Orgánica 2, 2010). Esta ley despenaliza la práctica del aborto durante las primeras catorce semanas, y entró en vigor el 5 de julio del 2010. Las justificaciones en torno al procedimiento abortivo contenidas en el preámbulo de esta ley parten de la premisa de la ineficacia de la normatividad vigente en esta materia. Al respecto, el legislador afirma:

La reforma del Código Penal supuso un avance al posibilitar el acceso de las mujeres a un aborto legal y seguro cuando si concurriera alguna de las indicaciones legales previstas: grave peligro para la vida o la salud física y psíquica de la embarazada, cuando el embarazo fuera consecuencia de una violación o cuando se presumiera la existencia de graves taras físicas o psíquicas en el feto. A lo largo de estos años, sin embargo, la aplicación de la Ley ha generado incertidumbres y prácticas que han afectado a la seguridad jurídica, con consecuencias tanto para la garantía de los derechos de las mujeres como para la eficaz protección del bien jurídico penalmente tutelado y que, en contra del fin de la norma, eventualmente han podido poner en dificultades a los profesionales sanitarios de quienes precisamente depende la vigilancia de la seguridad médica en las intervenciones de interrupción del embarazo. (Jefatura del Estado, 2010)

A este planteamiento se le suman los expresados en los textos internacionales en materia de los derechos de las mujeres, la violencia de género y los derechos asociados a la salud sexual y reproductiva, lo que invoca la Plataforma de Acción de Beijing. De igual manera, se hace gala de las declaraciones del Parlamento Europeo, que en este mismo sentido ha aprobado la Resolución 2001/2128(INI) sobre salud sexual y reproductiva y los derechos asociados, que contiene un conjunto de recomendaciones a los Gobiernos de los Estados miembros en materia de anticoncepción, embarazos no deseados y educación afectivo-sexual, y que tiene como base, entre otras consideraciones, la constatación de las enormes desigualdades entre las mujeres europeas en el acceso a los servicios de salud reproductiva, la anticoncepción y la interrupción voluntaria del embarazo en función de sus ingresos, su nivel de renta o el país de residencia (Jefatura del Estado, 2010).

Es menester señalar que la ley en comento, en sus artículos 13 y 14 consagra la despenalización de la praxis del aborto inducido en el lapso de las primeras catorce semanas del embarazo. En este plazo la mujer tendrá que decidir, en forma libre e informada, si desea interrumpir el embarazo, y sin intervención de terceros en su determinación. Así mismo, en el artículo 15 se establece la posibilidad de interrumpir el embarazo hasta la semana 22, cuando se presentan "graves riesgos para la vida o la salud de la madre o del feto"; específicamente en dos situaciones: cuando "se detecten anomalías en el feto incompatibles con la vida" o que "se detecte en el feto una enfermedad extremadamente grave e incurable en el momento del diagnóstico y así lo confirme un comité clínico" (Jefatura del Estado, 2010).

Como se ha afirmado, la mencionada Ley de Plazos modificó el ordenamiento jurídico contemplado en la Ley Orgánica 9 de 1985, que despenalizó el aborto en tres 
supuestos: el terapéutico, de riesgo físico o psíquico de la mujer embarazada; el criminológico, atinente a la violación, y el eugenésico correspondiente a las malformaciones físicas o taras en el feto ${ }^{14}$. El Código Penal impartía penas de prisión para la madre y los médicos que practicaban el aborto fuera de las circunstancias antes despenalizadas; es decir, se protegía como regla general el bien jurídico de la vida del nasciturus con el aborto como delito. No obstante, la actual Ley Orgánica 2 de 2010 dice cimentarse en los derechos fundamentales de la mujer, su salud sexual y reproductiva ${ }^{15}$.

Con base en el texto de la citada ley, ha emergido un debate sin precedentes en relación con el término salud sexual y reproductiva, insertado en el ámbito de los derechos humanos, la Bioética y el bioderecho, dentro de las biopolíticas públicas y los modelos de educación sexual; con posturas personalistas, de corte feminista y el ejercicio gubernamental sobre el estado de la cuestión del aborto a plazos. Ahora bien:

¿Está reconocido el aborto en los tratados y declaraciones internacionales de derechos humanos? Teniendo en cuenta la jurisprudencia constitucional española, ¿la vida humana intrauterina podría dejar de protegerse durante los primeros meses de gestación? En cuanto a la salud, ¿es el aborto una práctica recomendable para la mujer? ¿Puede proponerse como un método más de planificación familiar o al menos como último recurso para controlar la propia fecundidad cuando todos los demás han fallado? Y respecto de los profesionales que lo realizan, ¿es el aborto ético según sus códigos deontológicos? Por otro lado, las menores de edad que también acuden al aborto, ¿tienen capacidad para prestar su consentimiento o deben autorizarlo los padres? (González, 2009, p. 309)
Ante estos interrogantes, el Gobierno popular del presidente de España, Mariano Rajoy, a través de su ministro de Justicia, Alberto Ruiz-Gallardón, anunció la intención de reformar la Ley 2

de 2010, especialmente en lo concerniente al tema del aborto en los menores de 16 años sin el consentimiento de sus padres; se manifestó el propósito de retornar a lo consagrado en la Ley Orgánica 9 de 1985, donde palmariamente se alegaban los motivos de justificación para la pretendida decisión de abortar. La licitud de este se expresaba en los tres casos citados: por razones terapéuticas, criminológicas y eugenésicas; en cuanto a esta última, se pretende excluir de la justificación de aborto la malformación del feto. Por consiguiente, de aprobarse esta propuesta, se penalizaría el aborto con pena de prisión en los casos no amparados por la ley.

La intención del Gobierno es abandonar la Ley de Plazos para constituir una ley de supuestos de despenalización; se fundamenta en que la reforma obedece a instaurar "una ley de plazos que, por lo tanto, no ponga encima de la mesa la existencia de un conflicto entre el nasciturus y los derechos de la madre"16.

En su alocución, el ministro Ruiz-Gallardón afirma que la Ley de Plazos "roza la inconstitucionalidad"17. Adicionalmente, expresa que la reforma va en armonía con el Tribunal Constitucional, el cual estableció que, donde surgen conflictos entre dos bienes jurídicos protegidos, el legislador puede resolverlos, lo que no puede hacer es ignorar su existencia ${ }^{18}$.

En respuesta al ministro de Justicia, diversas posturas liberales, entre ellas las de feministas, argumentan que se pretende ocultar o "negar la libre elección de las mujeres ante un embarazo no deseado, no buscado, no querido, es en primer lugar, desconfiar de su criterio para valorar

En Estados Unidos el aborto está incluido a manera de derecho sexual y reproductivo de la mujer; ella es quien resuelve la posible interrupción o continuidad del embarazo, amparada en las políticas gubernamentales y las decisiones de los jueces. 
Bajo ninguna consideración deben ponderarse los derechos de un ser humano por encima del derecho a la vida de otro ser humano. La vida humana no se pondera, se respeta.

si en sus circunstancias pueden o deben seguir adelante con él." Continúan diciendo: "La legislación que el Estado debe procurar en relación con el aborto seguro, tiene que pasar necesariamente por confiar en el criterio de las mujeres a la hora de decidir si deben o pueden seguir adelante con un embarazo". Finalmente concluyen: "A las mujeres españolas nos ha costado más de 30 años llegar a conseguir este reconocimiento, pero parece que apenas nos va a durar un par de ellos" (Soleto, 2012).

En concordancia con lo expuesto, también se esgrime que no existe un sustento jurídico dentro de los estándares de los derechos humanos de la ONU y la jurisprudencia constitucional española para la eliminación de la causal de malformaciones. Se destaca, igualmente, el principio internacional de la "no regresividad" con respecto a los derechos económicos, sociales y culturales, dentro de los cuales están los derechos sexuales y reproductivos, que obligan a los Estados a no adoptar medidas que disminuyan el grado de disfrute de los derechos sociales adquiridos. Por tanto, España violaría los compromisos internacionales previamente ratificados en relación con los derechos sexuales y reproductivos ya conquistados (Fernández, 2012).

En el entorno constitucional, biopolítico y social de los Estados europeos, ante la posible modificación de la Ley de Plazos en el país ibérico, se denota, según un informe del Instituto de Política Familiar Español, que:

el 20 por ciento de los embarazos que se produjeron en 2011 no fueron interrumpidos, para un total de 118.359 abortos. Además, en los últimos años, las cifras se han disparado un 70 por ciento. $\mathrm{Si}$ se analizan las causas alegadas para estas interrupciones, el 89,58 por ciento de las mujeres no adujo ningún motivo (106.026 casos), mientras que 8640 abortos se practicaron por riesgo para la salud de la madre y 3234 por anomalías en el feto. (La Razón, 2013)

Es evidente que el debate en cuanto a la Ley Orgánica 2 de 2010 sobre salud sexual y reproductiva y la interrupción voluntaria del embarazo presenta disensos en relación con el alcance y el contenido referente al aborto inducido: unos apuntan a la defensa del comienzo de la vida humana del nasciturus y otros en favor de la vida de la madre, con base en los mismos fundamentos de la biopolítica, la biolegislación, la biojurisprudencia y las declaraciones y convenios de los organismos internacionales ratificados por España.

Aún se espera que se dilucide el recurso impetrado por el Partido Popular ante el Tribunal Constitucional español sobre esta ley, máxime que España ha sido el país de Europa con mayor crecimiento de abortos provocados en los últimos años. De hecho, "con un incremento del $70 \%$ ha pasado de 69.857 abortos en el 2001 a 118.359 abortos en el 2011" (IPF, 2013).

\section{ABORTO EN COLOMBIA: BIOJURISPRUDENCIA}

Para explicitar el tema de este artículo, sobre la cuestión de si el aborto es un derecho sexual y reproductivo de la mujer, nos corresponde contextualizarlo dentro del marco de las biopolíticas públicas colombianas; el bioderecho y la Bioética desde la mirada de la biojurisprudencia, expedida por la Corte Constitucional y el Consejo de Estado, en la aplicación e interpretación del alcance y el contenido de la Sentencia C-355 de 2006 y su reglamentación, mediante el Decreto 4444 del 13 de diciembre de 2006, por parte del Gobierno nacional a través del Ministerio de la Protección Social, las entidades territoriales, el Ministerio Público, la academia y los convenios internacionales actuales ratificados por Colombia.

A manera de antecedente, en la decisión jurisprudencial de la Corte Constitucional Colombiana, se ponderan los derechos sexuales y reproductivos de la mujer ante los del nasciturus, con la ratificación en el Congreso de Colombia 
del Protocolo de la Convención sobre la Eliminación de todas las Formas de Discriminación contra la mujer CEDAW (por sus siglas en inglés), que hizo trámite en el Congreso de Colombia y fue sancionado por el entonces presidente de la República, Álvaro Uribe Vélez ${ }^{19}$, y, análogamente, la demanda de inconstitucionalidad del artículo 122 del Código Penal contentivo en la Ley 599 de 2000 que cursó en la Corte Constitucional, impetrada por la abogada Mónica Roa ${ }^{20}$, confluyó en la despenalización del delito del aborto en Colombia bajo tres situaciones específicas, con la Sentencia C-355 del 2006: en caso de acceso carnal o acto sexual sin consentimiento, abusivo, de inseminación artificial o transferencia de óvulo fecundado no consentidas, o de incesto; malformaciones de feto incompatibles con la vida, y cuando se encuentre en peligro o riesgo la salud de la madre (Zárate Cuello, 2011, pp. 242-243). "La Corte Constitucional colombiana acogió para este fallo los planteamientos de la CEDAW sobre la violencia basados en sexo y género, en cuanto al derecho a la salud sexual reproductiva, el derecho al libre desarrollo de la personalidad" (Zárate, 2011, p. 251).

Posteriormente, el Ministerio de la Protección Social con el Decreto 4444 de 2006 reglamenta la prestación de unos servicios de salud sexual y reproductiva para garantizar el "goce efectivo en condiciones de igualdad y de seguridad dentro del sistema de seguridad social en salud" (Corte Constitucional, 2006), donde establece disponibilidad en el acceso a la interrupción voluntaria del embarazo en todo el territorio nacional para todas las mujeres y no vulnerar los derechos fundamentales protegidos por la Sentencia C-355/06. Con base en esta reglamentación, subsecuentemente se realizarían los abortos amparados en la Sentencia de la Corte Constitucional anteriormente citada.

Cabe anotar que durante la expedición del Decreto 4444 de 2006, su suspensión y nulidad, el procurador general de la nación expide acuerdos y circulares, entre ellas la 30 de 2009 donde solicita vehemente

A los servidores del Ministerio Público su mayor compromiso y disposición en defensa y protección de los derechos fundamentales de las mujeres gestantes, del derecho a la vida del no nacido y del derecho de los objetores de conciencia, así como en la vigilancia del cumplimiento de los deberes de los funcionarios públicos o de las personas que cumplen funciones públicas relacionados con las directrices de esta Circular. (Ordoñez, 2009)
Como reacción a estas y otras comunicaciones como la Circular 021 de 201121, emitidas por ese ente público, la organización Women Link Worldwide, dirigida por Mónica Roa, con la firma de 1279 mujeres, instaura una acción de tutela ante la Corte Constitucional contra el procurador general de la nación, Alejandro Ordoñez Maldonado; se argumentaba que "el Procurador no garantiza la plena vigencia de los derechos humanos porque ha usado su posición como jefe máximo del Ministerio Público para restringir el alcance de los derechos sexuales y reproductivos y no hacer cumplir las decisiones judiciales constitucionales" (Corte Constitucional, 2012), respecto de "la tergiversación sobre campañas sexuales, la píldora del día después, aborto en los tres casos, objeción de conciencia para los médicos y la entrega del misoprostol" (Reina, 2012).

La decisión de la tutela se profiere por parte de la Corte Constitucional mediante Sentencia T-627 del 10 de agosto de 2012, la cual resuelve que el procurador Alejandro Ordoñez rectifique los cinco puntos de la supuesta restricción de los derechos sexuales y reproductivos, impetrada en la tutela por parte de Women Link Worldwide 22 .

Cabe señalar que al Decreto nacional 4444 de 2006 que fuera demandado en acción pública de nulidad, como medida cautelar, se le declaró por parte del Consejo de Estado la suspensión provisional de sus efectos jurídicos hasta que se resolviera el fondo del asunto mediante sentencia (Procuraduría General de la Nación, 2009); habida consideración de

que la norma acusada desconoce el ejercicio de la potestad reglamentaria por parte del Gobierno, pues no existe ley objeto de reglamentación, expedida para regular el tema del aborto y la atención por parte de las entidades que conforman el Sistema General de Seguridad Social en Salud luego de la Sentencia C-355 de 2006 de la Corte Constitucional. (Rojas, 2013)

Se evidencia que el Procurador acató el fallo con su respectiva rectificación, aunque manifestó que: "es respetuoso del ordenamiento jurídico, tanto para cumplir las órdenes judiciales como para seguir defendiendo el derecho a la vida, desde la concepción hasta la muerte natural, de todas las mujeres y del más indefenso de los seres humanos: el que está por nacer" (Ordoñez, 2012). 
Posteriormente, mediante fallo de la Sección Primera del Consejo de Estado, del 13 de marzo de 2013, se declara nulo el Decreto 4444 de $2006^{23}$, bajo el entendido de que la potestad reglamentaria que consagra el artículo 189, numeral 11 de la Constitución Política de Colombia, "no puede ejercerse en abstracto, ni frente a actos jurídicos distintos de las leyes o decretos leyes" (Consejo de Estado, 2013, p. 56).

Es claro que lo proferido en el fallo del Consejo de Estado denota que de admitirse que el Ejecutivo expida una reglamentación con base en la sentencia sobre el tema del aborto en comento, "se llegaría al absurdo de entender que la sentencia hace las veces de ley y que el Gobierno nacional puede reglamentar una sentencia" (Procuraduría General de la Nación, 2009). Al declarar la Sección Primera del Consejo de Estado la improcedencia de la reglamentación de una sentencia por no tratarse de una ley o decreto ley, el Estado no puede financiar el aborto con recursos de la salud, obligar a nadie a practicarlo ni, mucho menos, imponerlo o sancionar con multas a quienes no acepten realizarlo, como lo ordenaba

la reglamentación del Gobierno (Consejo de Estado, 2009). De tal manera, se evidencia, con claridad meridiana, que el comienzo de la vida humana se encuentra actualmente en vilo en Colombia.

\section{CONCLUSIONES}

Al debatir sobre si el aborto es un derecho sexual y reproductivo de la mujer, cabe preguntarse, "¿se puede exigir ante los estrados judiciales como derecho?" (González, 2009). Teniendo en cuenta que el derecho de decisión que le asiste a la mujer sobre su reproducción y su cuerpo termina donde comienzan los derechos del nasciturus, cuyo límite se presenta en el instante mismo de la fecundación, el aborto no puede considerarse como un derecho humano; de lo que se trata es de la "pena de muerte prenatal", la palmaria violencia que ejerce la madre sobre el ser humano que se gesta en su vientre. Jamás podría considerarse como un derecho quitarle la vida a un miembro de su misma especie Homo sapienssapiens. Por tanto, bajo ninguna consideración deben ponderarse los derechos de un ser humano por encima del derecho a la vida de otro ser humano. La vida humana no se pondera, se respeta.

En relación con los postulados constitucionales de Estados Unidos de 1787, la Carta Magna Española de
1987 y la Constitución Política de Colombia de 1991, a todas luces cabría aducir la procreación como un derecho a la libertad que se concibe más como una expresión de libertad personal que como un derecho en el sentido propio. Por tanto, no puede considerarse como un derecho subjetivo que dé a los individuos facultades para exigir al Estado su realización, en virtud de que no está explícitamente consagrado. La mera positivización legal de una libertad no es suficiente para que se convierta en derecho $y$, mucho menos, en derecho fundamental (Abellán, 2011). Los derechos sexuales y reproductivos de la mujer conllevan implícita la libertad de procrear o no. Más aún, al discurrir acerca de

la libertad para decidir no engendrar, que constituye el contenido negativo de la salud reproductiva [...] La no aceptación de la procreación y su eliminación a través del aborto no puede argumentarse sobre la base de la libertad reproductiva, pues al tratarse del producto de la concepción de un nuevo ser, el aborto queda fuera del campo de la salud reproductiva. (González, 2009, p. 291)

Haciendo acopio de la reciente jurisprudencia que deja sin efectos jurídicos la potestad del Gobierno colombiano para reglamentar sentencias judiciales, y donde actuaba como magistrada ponente la consejera de Estado María Claudia Rojas Lasso, es preciso dilucidar que despenalizar no es regular ni conceder un derecho; en este caso, enmarcar como derecho sexual y reproductivo el aborto. De tal forma, "la Sentencia C-355 de 2006 no tuvo por objeto consagrar el derecho al aborto, sino despenalizar tres eventos en los cuales su práctica no es constitutiva de delito" (Consejo de Estado, 2013). Así mismo, la Plataforma de Acción de Beijing en ningún momento contempló el derecho al aborto como un derecho sexual y reproductivo de la mujer ${ }^{24}$. Se refirió a que:

Los Derechos Humanos de las mujeres incluyen su derecho a tener control y a decidir libre y responsablemente sobre los asuntos relacionados con su sexualidad, incluyendo su salud sexual y reproductiva y a estar libre de coerción, discriminación y violencia. La igualdad de las relaciones entre mujeres y hombres en materia de relaciones sexuales y reproducción, incluyendo el pleno respeto a la integridad de la persona, 
exige respeto mutuo, consentimiento y compartir la responsabilidad frente a la conducta sexual y sus consecuencias. (ONU, 1995b)

Esa maravillosa oportunidad que se le permitió a la mujer para el año 95 en Beijing frente a la complementariedad con el hombre que entraña la capacidad de disfrutar sin riesgos una vida sexual satisfactoria y de respeto mutuo en pareja; libre de coerción, discriminación y violencia; con igualdad y la posibilidad de contar con un sistema de seguridad en salud y el más alto nivel de bienestar; con el propósito de tener hijos o no, en ejercicio de la libertad de procreación, se soslayó con la bandera ProChoice que acompaña al grupo de mujeres feministas que proponen mundialmente el aborto como un derecho sexual y reproductivo de la mujer, cuyo fin último es el de propender que masivamente se despenalice el aborto en los Estados y en todas las circunstancias, como premisa fundamental de la equidad de género en la búsqueda de la igualdad de oportunidades con el hombre.

La anterior situación se hace plausible con la laxitud de la biojurisprudencia, teniendo como casos paradigmáticos a Estados Unidos, España y Colombia, principalmente, donde ha sido fácil masificar el aborto a partir del amparo de tres casos despenalizados, pero donde no existe el control de rigor judicial y científico que certifique que se

\section{Se está en presencia de unos nuevos valores} y derechos universales que se pretenden imponer con carácter absoluto, que trascienden las fronteras, se inmiscuyen en la cultura, y prevalecen sobre los derechos de las personas está en presencia de uno de los tres casos. Ergo, se abre la ancha rendija para liberalizar el aborto cobijándose en estos tres supuestos no punibles, donde las biopolíticas públicas en materia de salud reproductiva se alejan de una Bioética comprometida con los seres humanos que claman dignidad.

"La transformación de delito en derecho niega la verdad y entrama en una corrupción la norma moral, la perversión de la persona" (Lucas, 2001, p. 3), por lo que se discrimina a la mujer y al nasciturus dentro del Estado social de derechos, cuya función es la de propender por los derechos humanos, incluyendo los de la salud sexual y reproductiva sin eufemismos, para que no se designen prácticas que al ser nombradas como debe ser causen mayor efecto moral, lo que conduce a una ambivalencia en la cual, por un lado, se pretende brindar protección a la dignidad de la vida humana de la mujer mediante la despenalización de unas conductas que, por otro lado, sientan las bases para la total indiferencia hacia los derechos humanos del nasciturus, "que niegan la personalidad del embrión [pues] se basan en un desconocimiento de irrefutables datos científicos o en concepciones antropológicas que no reconocen el valor de la persona por sí misma" (Pastor, 1997). A partir de lo anterior, proliferan prácticas eugenésicas que eran penalizadas anteriormente; se logra conseguir eliminar la penalización de dichas conductas a medida que la sociedad las acepta, preconizando el aborto como derecho sexual y reproductivo de la mujer en todas las circunstancias, como premisa fundamental de la dignidad humana en pos de reconocer la libertad sin límites como el principio rector de la sociedad.

Del tamizaje realizado en relación con el presente estudio, se elucida que a causa de las diferencias en los campos de desarrollo económico, político, social y la aplicación de los avances tecnocientíficos en Estados Unidos, España y Colombia, se dan distintas respuestas ante las particularidades de los problemas y los polilemas que se plantean en relación con el aborto. A contrario sensu, se observa que se está en presencia de unos nuevos valores y derechos universales que se pretenden imponer con carácter absoluto, que trascienden las fronteras, se inmiscuyen en la cultura, y prevalecen sobre los derechos de las personas, priorizando el principio de autonomía de la mujer frente a los de justicia, beneficencia y no maleficencia. 
Por ende, el bioderecho, la Bioética, la biopolítica y la biojurídica deben construir un discurso dialógico sobre los derechos humanos del nasciturus, normatizando "los límites de la autonomía de la madre y el médico, la dignidad de esa vida humana por nacer y el deber de justicia de proteger su vida" (León, 2010), como el mejor regalo para la permanencia de la especie humana en la Tierra, abanderando a una sola voz la protección de los derechos sexuales y reproductivos de la mujer con equidad, en ejercicio de los derechos individuales y colectivos, ante los desafíos del mundo contemporáneo en defensa de la vida.

\section{NOTAS}

(uscriminación contra la mujer como: "Cualquier distinción, exclusión o restricción hecha en base al sexo que tenga el efecto o propósito de disminuir o nulificar el reconocimiento, goce y ejercicio por parte de las mujeres, independientemente de su estado civil, sobre la base de igualdad del hombre y la mujer, de los derechos humanos y libertades fundamentales en las esferas política, económica, social, cultural, civil o en cualquier otra esfera" (Protocolo Facultativo de la Convención sobre la Eliminación de Todas las Formas de Discriminación contra la Mujer, 1979).

2 El texto original expresa: "All couples and individuals have the basic human right to decide freely and informedly the number and spacing of their children; maternal and child health and family-planning components

of primary health care should be strengthened; and family-planning information should be produced and services created. Access to such services should be encouraged by Governments irrespective of their population policies and should be carried out with the participation of women's organizations to ensure their success" (Organización de las Naciones Unidas, 1995a).

3 Morlachetti (2007), para la celebración de la Conferencia Internacional sobre la Población y el Desarrollo (El Cairo, 5 al 13 de septiembre de 1994), se congregaron representantes de más de 180 países, número sin precedentes de países y organizaciones participantes (Naciones Unidas, 1994). El Programa de Acción aprobado se sometió al examen de la Asamblea General de las Naciones Unidas que, reunida en una sesión extraordinaria en junio de 1999, evaluó los progresos ya realizados, revisó las dificultades subsistentes, presentó recomendaciones y propuso medidas prácticas para alcanzar los objetivos de la Conferencia en los próximos veinte años. Esta evaluación es el resultado de un largo proceso, llamado $\mathrm{CIPD}+5$, en el que participaron activamente organizaciones no gubernamentales, Gobiernos y organismos internacionales. Para ampliar esta información, cfr. Examen y evaluación de la declaración y la plataforma de acción de Beijing y el documento final del vigésimo tercer periodo extraordinario de sesiones de la Asamblea General (2000) en países de América Latina y el Caribe (LC/L.3175) y Morlachetti, A. (s. f.).

4 El texto original en su párrafo 216 dice: "The human rights of women include their right to have control over and decide freely and responsibly on matters related to their sexuality, including sexual and reproductive health, free of coercion, discrimination and violence" (Organización de las Naciones Unidas, 1995a).

5 Para Angela Aparisi, "el bioderecho abordaría el estudio de las realidades o 'fenómenos bioéticos' es decir, de los diversos conflictos que surgen en el ámbito de las relaciones humanas, como consecuencia de la incorporación de las nuevas tecnologías a las ciencias de la salud", desde la perspectiva de la ciencia jurídica" (2007).
Sobre el ejercicio de la biojurídica, Ángela Aparisi afirma: "La función de la biojurídica será, precisamente, la de justificar aquellos principios, no morales, sino propiamente jurídicos, en los que se apoyaría el bioderecho o la biolegislación" (2007). También Palazzani dice: "Los términos 'biojurídica' y 'bioderecho' (distintos en la lengua italiana, pero indistintos en otras lenguas) remiten a disciplinas académicas encuadradas, respectivamente, en el ámbito de la filosofía del derecho y del derecho privado" (2002).

7 Griswold (1965) fue la culminación de una batalla de cincuenta años para organizar una oposición formal a las leyes de control de natalidad (Garrow, 1993).

8 "Roe V. Wade (1973): The battle began in Texas, which outlawed any type of abortion unless a doctor determined that the mother's life was in danger. The anonymous Jane Roe challenged the Texas law, and instituted federal action against Henry Wade, the district attorney of Dallas County, Texas, where Roe resided. Thus the case slowly made its way to the highest court in the land. After two years of hearing evidence, the Court invalidated the Texas law by a 7-2 vote. Using the same reasoning as the Griswold v. Connecticut decision, the majority of the justices maintained that a right to privacy was implied by the Ninth and Fourteenth Amendments. No state could restrict abortions during the first three months, or trimester, of a pregnancy" (USHistory.org, 2008).

9 "El voto por la mayoría del Juez Blackmun trata al aborto de modo diferente durante los tres trimestres de un embarazo normal:

(1) Durante el estadio anterior a aproximadamente el fin del primer trimestre, la decisión de abortar y su realización debe ser dejada al criterio del médico de cabecera de la mujer embarazada.

(2) Durante el estadio siguiente a aproximadamente el fin del primer trimestre, el Estado, en la promoción de su interés por la salud de la madre, puede, si elige hacerlo, regular el procedimiento abortivo en modos que estén razonablemente relacionados con la salud maternal.

(3) Durante el estadio siguiente a la viabilidad, el Estado, en la promoción de su interés en la potencialidad de vida humana, puede, si elige hacerlo, regular, y hasta prohibir, el aborto excepto cuando es necesario, de acuerdo a un apropiado criterio médico, para la preservación de la vida o la salud de la madre" (Blackmun, 1973410 U.S. 113 [1973], pp.164-165

10 Definición de Pro-Choice: "The social movement that became known as the 'pro-choice' movement originated in the 1960s as a loose coalition of women's movement, single-issue 'abortion' movement, and population movement activists and organizations" (Staggenborg, 1991).

11 Respecto al tema, "la Corte Suprema sostuvo que una ley de Pennsylvania colocaba una carga indebida sobre las mujeres en tanto exigía a una mujer casada que buscaba un aborto firmar una declaración de que había notificado a su esposo [...] en el caso de una menor, debe existir el consentimiento informado de por lo menos uno de los padres como mínimo veinticuatro horas antes del procedimiento" (Shapiro, 2009, p. 11). 

propósito, o el efecto, de poner un obstáculo sustancial a una mujer que decide abortar un feto no viable" (Corte Suprema, 1992, pp. 845-46). Nebraska que lo vedaba, como "extraer intencionalmente de la vagina un niño vivo no-nacido, o una porción sustancial del mismo, con el propósito de realizar un procedimiento que los [abortistas] saben que matará al... niño y de hecho... lo hace. [...] la ley de Nebraska convirtió en delito practicar un aborto por nacimiento parcial a menos que fuera necesario para salvar la vida de la madre" (530 U.S. 914, at p. 922, 2000, en Shapiro, 2009).

14 Este procedimiento, relativamente inusual, fue definido por la Ley de Nebraska que lo vedaba como "extraer intencionalmente de la vagina un niño vivo no-nacido, o una porción sustancial del mismo, con el propósito de realizar un procedimiento que los [abortistas] saben que matará al... niño y de hecho... lo hace [...] la ley de Nebraska convirtió en delito practicar un aborto por nacimiento parcial a menos que fuera necesario para salvar la vida de la madre" (530 U. S. 914, at p. 922, 2000, en Shapiro, 2009).

"Desde noviembre de 2008 hasta octubre de 2012, suma hasta 241 iniciativas al servicio a la cultura de la muerte, incluida la obligación, con su reforma sanitaria, de que las instituciones públicas paguen abortos o, su liberticida 'Obamacare'" (Házte Oír, 2012). LO9/1985, vigente según la Disp. Derogatoria Única 1. a) de la LO 10/1995 del Código Penal.

17 Artículo 1 de la Ley Orgánica de Salud Sexual y Reproductiva y de la Interrupción Voluntaria del Embarazo: "Constituye el objeto de la presente ley orgánica garantizar en un entorno libre de coerción, discriminación y violencia, los derechos fundamentales en el ámbito de la salud sexual y reproductiva, regular las condiciones de la interrupción voluntaria del embarazo y establecer las correspondientes obligaciones de los poderes públicos" (Recuperado el 23 de marzo de 2013 del sitio de Internet del BOE: https://www.boe.es/buscar/doc.php?id=BOE-A-2010-3514).

18 El ministro de Justicia alega que dicha reforma se apoya en "un mandato de Naciones Unidas y un convenio suscrito por la nación española y aprobado por unanimidad en el Congreso de los Diputados que nos obliga a ello" (Velasco, 2013).

19 El Ministro Ruiz-Gallardón expresa: "Pensamos que la desprotección absoluta del nasciturus y permitir la no viabilidad de su proyecto de vida sin acreditar la existencia de un conflicto que así lo justifique es inconstitucional" (La Razón, 2013).

20 Cfr. Diario La Razón (http://www.larazon.es/detalle_normal/noticias/687630/ la-nueva-ley-del-aborto-estara-lista-antes-de\#.UWO-h6KOVe_) y consultar Tribunal Constitucional Español: Sentencias STC 53/85, STC 116/99 y STC 212/96 en http://hj.tribunalconstitucional.es/HJ/es-ES/Resolucion/List.

El 16 de agosto de 2005, el presidente Álvaro Uribe sanciona la Ley 984 de 2005, por medio de la cual se ratifica el Protocolo Facultativo de la Convención sobre Eliminación de Todas las Formas de Discriminación contra la Mujer. De igual manera, mediante la Sentencia C-322-06, la Corte Constitucional Colombiana declaró exequible el mencionado protocolo (http://www.iidh.ed.cr/comunidades/derechosmujer/Acerca/Colombia/ colombia.htm).

Mónica Roa es directora de programas de Women's Link (http://www. womenslinkworldwide.org/who_staff_roa.html).
“El 25 de marzo de 2011 el Procurador General de la Nación emitió un comunicado, en el que señala que el derecho internacional de los derechos humanos prohíbe el aborto y protege el derecho a la vida de forma absoluta y desde la concepción". Tal comunicado se dio con ocasión del llamado Día Internacional de la Vida o Día Internacional del Niño y la Niña por Nacer. Se dirigió "a todos los ciudadanos, las instituciones, las autoridades y los servidores públicos que directa e indirectamente realizan labores en favor de los derechos y la protección de los niños y las niñas por nacer" (Corte Constitucional, 2012).

24 "En el sentido de explicar que incurrió en una equivocación al referirse a las campañas ordenadas en la sentencia T-388 de 2009 como 'campañas masivas de promoción del aborto como derecho' ya que, en realidad, estas buscan promover que las mujeres colombianas conozcan el contenido de sus derechos sexuales y reproductivos, dentro de los cuales se encuentra la interrupción voluntaria del embarazo en las hipótesis despenalizadas". Igualmente modifique: "la posición oficial de la Procuraduría General de la Nación en el sentido de que, en Colombia, la anticoncepción oral de emergencia (i) no tiene carácter abortivo sino anticonceptivo, (ii) su uso no está restringido a las hipótesis despenalizadas de aborto, (iii) las mujeres que hacen uso de ella fuera de las causales despenalizadas de aborto no incurren, en ningún caso, en el delito de aborto y (iv) hace parte de los servicios de salud reproductiva que las mujeres colombianas pueden libremente elegir", y, de igual forma, "Ios considerandos de la Circular 029 de 2010 para (i) eliminar aquel de acuerdo con el cual 'como consecuencia de dicha decisión de suspensión provisional y entre tanto el Consejo de Estado no resuelva de fondo la constitucionalidad del Decreto 4444 de 2006, ninguna autoridad judicial o administrativa puede restringir el derecho constitucional a la objeción de conciencia (artículo 18 de la CP) cuando este se invoque en oposición a la práctica de un aborto, el cual deberá protegerse [...]' y (ii) remplazarlo por uno en el que se describan claramente los límites que la jurisprudencia constitucional ha fijado para la objeción de conciencia a la IVE, tal y como fueron resumidos en el numeral 82 de la parte motiva de la presente sentencia. En el mismo término, se deberán comunicar las modificaciones de la Circular a sus destinatarios". Ordena también: "eliminar del numeral 8 de la primera directriz de la Circular 021 de 2011 toda referencia al derecho de las instituciones a objetar conciencia o la posibilidad de su ejercicio colectivo, en lo que toca con la IVE" así mismo "levante la suspensión de la decisión acerca de la inclusión del principio activo misoprostol en el Plan

Obligatorio de Salud y, en consecuencia, continúe su trámite desde la etapa en la cual fue suspendido" (cfr. documento Sentencia T-627-12, Corte Constitucional de Colombia, 2012).

25 Por solicitud de la Procuraduría se tramita el 27 de julio del 2012 el alegato de nulidad del citado Decreto 4444 de 2006 (recuperado de http://www.procuraduria.gov. co/portal/media/file/Nulidad\%20por\%20 Inconstitucionalidad.pdf).

26 "We acknowledge that we find no wording in the UN international Treaties regarding the words 'SEXUAL and REPRODUCTIVE RIGHTS'" (ID del documento de ProQuest: 231069626. URL del documento: http://search.proquest.com/docview/231069626? accountid=30799. Copyright: Copyright Women's International Network Autumn 1998. Última actualización: 2010-06-10). 
REFERENCIAS

- Abellán García, F. (2011). Derecho a la procreación. En C. M. Romero Casabona (Director), Enciclopedia de bioderecho y Bioética (t. I, p. 570). Granada: Editorial Comares.

AMECOPRESS (2008). Gloria López. El aborto en Estados Unidos: la doble moral. Recuperado el 11 de marzo de 2013 de http:// amecopress.net/spip.php?article1253

Aparisi, A. (2002). Introduzione alla biogiuridica. Torino: Giappichelli. Aparisi, A. (2007). Bioética, bioderecho y biojurídica (Reflexiones desde la filosofía del derecho). Anuario de Filosofía del Derecho, XXIV, pp. 64-84.

- Berer, M. (2009). The Cairo "compromise" on abortion and its consequences for making abortion safe and legal. En L. Reichenbach y M. Roseman (Eds.), Reproductive health and human rights: The way forward (pp. 152-163). Pennsylvania: University of Pennsylvania Press.

- Cassata, D. (3 de septiembre de 2012). AssociatedPress. Plataforma demócrata que apoya aborto y bodas gay. Recuperado el 15 marzo de 2013 http://news.yahoo.com/dems-platform-backs-gay-marriage-abortionrights-020730209--election.html

- Consejo de Estado (2009). Auto del 15 de octubre de 2009. Recuperado de http://www.ambitojuridico.com/Banco Conocimiento/N/ noti12041008(consejo_de_estado_dara_prelacion_a_accion_de_nulidad_ contra_decreto_reglamentario_de)/noti12041008(consejo_de_estado_ dara_prelacion_a_accion_de_nulidad_contra_decreto_reglamentario_de). asp? Miga $=1 \&$ CodSeccion $=84$

- Consejo de Estado, Sección Primera (13 de marzo de 2013). Sentencia 20080025600 de nulidad del Decreto 4444 del 2006. Recuperado de http:// es.scribd.com/doc/131839809/Sentencia-de-nulidad-decreto-4444

- $\quad$ Corte Constitucional (2006). Decreto 4444 de 2006. Recuperado el 30 de marzo de 2013 de http://www.alcaldiabogota.gov.co/sisjur/normas/ Norma1.jsp?i=22421

- Corte Constitucional (2012). http://www.corteconstitucional.gov.co/ relatoria/2012/t-627-12.htm

- Corte Suprema (29 de junio de 1992). Caso Planned Parenthood v. Casey. U. S. Reports, 505, 845-46.

- CTVNews (2013). 40 years after U.S. abortion ruling, opponents still seek new restrictions. Recuperado el 18 de marzo de 2013 de http://www. ctvnews.ca/world/40-years-after-u-s-abortion-ruling-opponents-still-seeknew-restrictions-1.1124491

- Declaración de Viena y Programa de Acción de la Conferencia Mundial sobre Derechos Humanos (14-25 de junio de 1993). Recuperado el 3 de marzo de 2013 de http://www.unhchr.ch/huridocda/huridoca.nsf/ (Symbol)/A.CONF.157.23.Sp?OpenDocument

- El engañoso argumento sobre el aborto y la malformación del feto. Recuperado el 26 de marzo de 2013 de http://www.huffingtonpost.es/ teresa-fernandez-paredes/el-enganoso-argumento-sob_1_b_2093245.html Gallup (2013). Lydia Saad. Majority of AmericansStillSupport Roe v. WadeDecision. Recuperado el 18 de marzo de 2013 de http://www.gallup. com/poll/160058/majority-americans-support-roe-wade-ecision.aspx?utm_ source=alert\&utm_medium=email\&utm_campaign=syndication\&utm_ content $=$ morelink\&utm_term $=$ All

- Garrow, D. J. (1993). The right to privacy and the making of Roe v. Wade. New York: Lisa Drew Books.

- George, R. (enero 22 de 2009). Our struggle for the soul of our nation. Recuperado el 20 de marzo de 2013 de http://www.thepublicdiscourse. com/2009/01/96/

- González, M. C. (2009). Sexualidad y aborto, ¿cuestión de salud?, ¿cuestión de derechos? Anuario de Derechos Humanos. Nueva Época, 10, 291.
- Házte oír (2012). Obama, auténtico plusmarquista en la imposición de la cultura de la muerte. Recuperado el 20 de marzo de 2013 de http://www. hazteoir.org/noticia/49126-obama-autentico-plusmarquista-en-imposicioncultura-muerte

- Instituto de Política Familiar - IPF (24 de enero de 2013). Recuperado el 28 de marzo de 2013 de www.ipfe.org

- Jefatura de Estado (2010). Ley orgánica 2/2010 del 3 de marzo de salud sexual y reproductiva y de la interrupción voluntaria del embarazo. BOE-A-2010-3514.

- La Razón (2013). Recuperado el 25 de marzo de 2013 de http://www. larazon.es/detalle_normal/noticias/1757299/sociedad+salud/ el-plazo-parael-aborto-libre-en-espana-de-lo\#.UWO4FaKOVe8

- León, F. (2010). El aborto desde la Bioética: ¿autonomía de la mujer y del médico? Cuadernos de Bioética, 21(71), 79-93.

- Lucas, R. (2001). La naturaleza humana del embrión. En Antropología y problemas bioéticos (p. 3). Madrid: BAC.

- Miller, A. M. y Roseman, M. J. (november, 2011). Sexual and reproductive rights at the United Nations: frustration or fulfilment? Reproductive Health Matters, 19(38), 102-118.

- Morlachetti, A. (s. f.). Políticas de salud sexual y reproductiva dirigidas a adolescentes y jóvenes: un enfoque fundado en los derechos humanos. Notas de Población, 85. Recuperado el 5 de marzo de 2013 de http://www. eclac.cl/publicaciones/xml/1/32261/lcg2346-P_4.pdf

- Mundo.es. (2013). Cuarenta años después, el aborto sigue dividiendo a los estadounidenses. Recuperado el 15 de marzo de 2013 de http://www. elmundo.es/america/2013/01/23/estados_unidos/1358899578.html

- Ordoñez, A. (2009). Circular 30 del 2009, Procuraduría General de la Nación. Recuperado de http://www.consultorsalud.com/biblioteca/circulares/ Circular\%2030\%202009\%20PGN\%20-\%20aborto.pdf

- Organización de las Naciones Unidas (ONU). (1979). Protocolo Facultativo de la Convención sobre la Eliminación de Todas las Formas de Discriminación contra la Mujer disponible. Recuperado el 25 de febrero de 2013 de http:// www.un.org/womenwatch/daw/cedaw/text/sconvention.htm

- Organización de las Naciones Unidas (ONU). (1985). World conference to review and appraise the achievements of the United Nations Decade for Women: Equality, Development and Peace. Recuperado de http://www. un.org/womenwatch/daw/beijing/otherconferences/Nairobi/Nairobi\%20 Full\%200ptimized.pdf

- Organización de las Naciones Unidas (ONU). (1993). Conferencia Mundial de Viena sobre Derechos Humanos. Recuperado de http://daccess-dds-ny. un.org/doc/UNDOC/GEN/G93/142/36/PDF/G9314236.pdf?OpenElement

- Organización de las Naciones Unidas (ONU). (1994). Informe de la Conferencia Internacional sobre la Población y el Desarrollo. El Cairo. Recuperado de https://www.unfpa.org/webdav/site/global/shared/ documents/publications/2004/icpd_spa.pdf

- Organización de las Naciones Unidas (ONU). (1966). Asamblea General de las Naciones Unidas. Resolución XXI laprobada durante el $21^{\circ}$ periodo de sesiones). Recuperado el 28 de febrero de 2013 de http://www.un.org/ spanish/documents/ga/res/21/ares21.htm

- Organización de las Naciones Unidas (ONU). (1968). Proclamación de la Conferencia Internacional de Derechos Humanos en Teherán. Numeral 16. Recuperado el 28 de febrero de 2013 de http://www.unhchr.ch/spanish/ $\mathrm{html} / \mathrm{menu} 3 / \mathrm{b} / \mathrm{b} \_$tehern_sp.htm

- Organización de las Naciones Unidas (ONU). (1995a). Informe de la Conferencia Internacional sobre la Población y el Desarrollo. El Cairo, 5 a 13 de septiembre de 1994. A/CONF.171/13/Rev.1, ISBN 92-1-351116-7. 
Recuperado el 5 de marzo de 2013 de http://daccess-dds-ny.un.org/doc/ UNDOC/GEN/N95/231/29/PDF/N9523129.pdf?OpenElement

Organización de las Naciones Unidas (ONU). (1995b). Página de las Naciones Unidas. Cuarta Conferencia Mundial sobre la Mujer Beijing, 1995. Recuperado el 10 de marzo de 2013 de http://www.un.org/esa/gopherdata/conf/fwcw/off/a-20.en

- Organización de las Naciones Unidas (ONU). (2002). Documento final del vigésimo tercer periodo extraordinario de sesiones de la Asamblea General en países de América Latina y el Caribe (LC/L.3175).

- Parker, A. (2013). 40 years after Roe v. Wade, thousands march to oppose abortion. Recuperado el 17 de marzo de 2013 de http://www.nytimes. com/2013/01/26/us/politics/40-years-after-roe-v-wade-thousands-march-tooppose-abortion.html?_r $=0$

- Pastor, L. M. (1997). Bioética y aborto. En L. M. Pastor y F. J. León, Manual de ética y legislación en enfermería (p. 243). Madrid, España: Editorial Mosby.

- Procuraduría General de la Nación (2009). Consejo de Estado. Recuperado el 10 de marzo de 2013 de http://www.procuraduria.gov.co/portal/ media/file/descargas/2011/AnexosBoletinMisoprostol/2-Auto\%20Consej oEstado.pdf

- Protocolo Facultativo de la Convención sobre la Eliminación de Todas las Formas de Discriminación contra la Mujer (1979a). (Artículo 12). Resolution 34/180, Official Records of the General Assembly of the United Nations, Thirty-fourth Session, Supplement No. 46 (A/34/46) (p. 195). Recuperado el 28 de febrero de 2013 de http://www.un.org/womenwatch/ daw/cedaw/ text/sconvention.htm

- Reina, D. (2012). Mónica Roa: "No queremos que el procurador vaya a la cárcel". Revista Semana. Recuperado de http://www.semana.com/nacion/ articulo/monica-roa-no-queremos-procurador-vaya-carcel/265019-3

- Rojas Lasso, M. C. (13 de marzo de 2013). Sentencia de nulidad Decreto 4444 del 2006. Recuperado de http://es.scribd.com/doc/131839809/ Sentencia-de-nulidad-decreto-4444

- Shapiro, I. (2009). El derecho constitucional al aborto en los Estados Unidos: una introducción en Doxa. Cuadernos de Filosofía del Derecho, 31, 9.

- Staggenborg, S. (1991). The pro-choice movement: Organization and activism in the abortion conflict. Oxford: Oxford University Press.

- Soleto (2012). Recuperado el 25 de marzo de 2013 de http://www. huffingtonpost.es/marisa-soleto-avila/gallardon-y-el-aborto_b_1697239.html. USHistory.org (2008). 57d. Roe v. Wade and Its/mpact. Recuperado el 11 de marzo de 2013 de http://www.ushistory.org/us/57d.asp

- Velasco, F. (2013). La nueva ley del aborto estará lista este trimestre. Diario La razón. Recuperado el 23 de marzo de 2013 de http://www.larazon.es/ detalle_normal/noticias/687630/la-nueva-ley-del-aborto-estara-lista-antesde\#.UWQ-h6KOVe

- Zárate Cuello, A. (21 de diciembre de 2011). El bioderecho como instrumento en la determinación de los límites a la libertad de investigación: especial referencia a la eugenesia positiva en genética humana. Madrid, España. 